\title{
Caregiver rating of provider participatory decision-making style and caregiver and child satisfaction with pediatric asthma visits
}

\author{
Betsy Sleath, PhD*, \\ Professor, University of North Carolina Eshelman School of Pharmacy \& Research Associate, \\ Cecil G. Sheps Center for Health Services Research, University of North Carolina at Chapel Hill.
}

Guadalupe X. Ayala, PhD, MPH,

Associate Professor in the Division of Health Promotion and Behavioral Science in the Graduate, School of Public Health at San Diego State University.

Deidre Washington, PhD,

Postdoctoral Fellow, Pharmaceutical Outcomes \& Policy, University of North Carolina at Chapel Hill Eshelman School of Pharmacy

Stephanie Davis, MD,

Associate Professor in Pediatrics, University of North Carolina at Chapel Hill School of Medicine

Dennis Williams, PharmD,

Associate Professor, University of North Carolina Eshelman School of Pharmacy, University of North Carolina at Chapel Hill.

Gail Tudor, PhD,

Professor and Chair, Department of Science and Mathematics, Husson University, Bangor Maine

Karin Yeatts, PhD, and

Research Assistant Professor, Department of Epidemiology, UNC McGavran-Greenberg Hall at Chapel Hill

Chris Gillette, PhD Candidate

PhD student in Pharmaceutical Outcomes \& Policy, University of North Carolina at Chapel Hill

Eshelman School of Pharmacy

\section{Abstract}

Objectives-The purpose of this study was to examine the relationship between caregiver ratings of provider use of a participatory decision-making style and caregiver and child satisfaction with their pediatric asthma visits.

Methods-Children ages 8 through 16 with persistent asthma and their caregivers were recruited at five pediatric practices. Children were interviewed and caregivers completed questionnaires after their child's medical visits. Generalized estimating equations were used to analyze the data.

Results-Three hundred and twenty children were recruited. Caregivers were significantly more satisfied with providers who they perceived as using more of a participatory decision-making style (beta $=17.80, p<0.001)$. Children (beta $=-0.10, \mathrm{p}<0.05)$ and caregivers (beta $=-0.21, \mathrm{p}<0.01$ ) were

\footnotetext{
(C) 2010 Elsevier Ireland Ltd. All rights reserved.

"Corresponding author: bsleath@email.unc.edu.
}

Publisher's Disclaimer: This is a PDF file of an unedited manuscript that has been accepted for publication. As a service to our customers we are providing this early version of the manuscript. The manuscript will undergo copyediting, typesetting, and review of the resulting proof before it is published in its final citable form. Please note that during the production process errors may be discovered which could affect the content, and all legal disclaimers that apply to the journal pertain. 
significantly more satisfied with younger providers. Children were significantly more satisfied with providers who knew them better as a person (beta $=2.87, \mathrm{p}<0.001$ ).

Conclusions-Caregivers were more satisfied with providers who they perceived as involving them more during treatment decisions made during pediatric asthma visits.

Practice implications-Providers should attempt to use a more participatory decision-making style with families during pediatric asthma visits.

\section{Keywords}

asthma; participatory decision-making style; pediatrics; satisfaction; health care providers

\section{Introduction}

Asthma is a worldwide problem and it is the most common chronic condition among American children [1]. There are more than 7 million children under age 18 in the United States with asthma [2]. Healthcare costs for asthma are estimated at more than 6 billion dollars a year and loss in productivity by working parents caring for children who miss school due to asthma is estimated at one billion dollars a year [3,4].

Little prior work has examined caregiver and child satisfaction with pediatric asthma visits [5]. Wissow et al. [5] found that provider use of a patient-centered style during pediatric asthma emergency room visits was associated with higher parent ratings of good care. Clark et al. [6] found that positive perceptions of physician performance by parents of asthmatic children were significantly related to parent reports of provider behaviors such as careful listening, inquiring about home management, interactive conversation, tailoring short term goals, and long term therapeutic plan. In a sample of adults with asthma, Adams et al. [7] found that patients who rated their physicians as using a more participatory decision-making style were more satisfied with their medical visits.

Hart et al. [8] found parents who rated providers better on certain aspects of provider-parent communication (collaborating on treatment planning and mutual understanding) were more satisfied with their visits. Freed et al. [9] found that provider style was strongly related to adolescent satisfaction with their health care providers.

Therefore, we wanted to examine how caregiver ratings of provider use of a participatory decision-making style were related to child and caregiver satisfaction with pediatric asthma visits because asthma is a chronic disease and current national asthma guidelines in the United States state that providers should involve children and caregivers in treatment decisions [10]. The purpose of this study was to examine the relationship between caregiver ratings of provider use of a participatory decision-making style and caregiver and child satisfaction with their pediatric asthma visits.

\section{Methods}

\subsection{Participants}

Five pediatric practices and forty-one providers agreed to participate in the study. Children were eligible if they: (a) were ages 8 through 16 years, (b) were able to speak English, (c) could read the assent form, (d) had been seen at the clinic at least once before, (e) were present at the visit with an adult caregiver (parent or legal guardian) who could read and speak English and who was at least 18 years of age, and (f) had mild, moderate, or severe persistent asthma. Persistent asthma was defined as experiencing asthma-related daytime 
symptoms more than twice a week, asthma-related nighttime symptoms more than twice a month, or receiving one or more long-term controller therapies for asthma [3,11].

\subsection{Procedure}

The study was approved by the University of North Carolina Institutional Review Board. Children and their caregivers were recruited at five pediatric practices in non-urban areas of North Carolina. Clinic staff referred potentially eligible patients who were interested in learning more about the study to a research assistant. The research assistant explained the study, obtained caregiver consent and child assent, and administered the eligibility screener [3]. Eligible children were interviewed after their medical visits and caregivers completed self-administered questionnaires.

\subsection{Measures}

A 12-item Child Satisfaction Questionnaire measured provider-child rapport and the child's comfort with communication during the medical visit [12]. Child scores could range from 12 to 60 on the scale. Caregiver satisfaction was measured using the 26-item Caregiver Medical Interview Satisfaction Scale. Caregiver scores could range from 26 to 182 [12-14].

Participatory decision-making style was measured using the 3-item scale developed by Kaplan et al. [15]. A summary score ranging from 0 to 100 was calculated. Higher scores reflected caregivers rating their children's physicians as being participatory. Participatory decision-making style was then recoded into a dichotomous variable (score less than 70, score 70 or greater) $[15,16]$.

Asthma severity was classified as mild versus moderate/severe by a research assistant based on recent symptoms and medication use reported by the caregivers on the eligibility screening instrument $[3,17,18]$. All child study information was then reviewed by a pediatric pulmonologist or a clinical pharmacist with expertise in asthma to verify the severity classification.

The number of years the child had asthma was calculated by asking the caregiver the age at which the child was diagnosed with asthma and subtracting this from the child's age. For descriptive purposes, child, caregiver, and provider race were recoded into four categories: White, African American, Native American/American Indian, or Other. However, for the multivariate analyses, race was recoded into dichotomous variables (White versus nonWhite). Length of the visit was measured in minutes.

\subsection{Statistical Analysis}

First, we present descriptive statistics. Second, we examined the bivariate relationships between the variables using Pearson correlation coefficients, chi-square statistics, and t-tests. Third, we conducted a generalized estimating equation (GEE) to examine how the characteristics listed in Table 3 were associated with child satisfaction. Finally, we conducted a GEE to examine how the characteristics listed in Table 4 were associated with caregiver satisfaction. In both of the GEEs we nested by provider.

\section{Results}

Forty-one providers agreed to participate in the study. Two providers refused for a participation rate of $95 \%$. Eighty-eight percent of the families approached agreed to participate in the study. Three hundred and twenty children and caregivers participated. Table 1 presents the demographic characteristics. Forty percent of the children saw female providers, 89\% saw White providers, and provider age ranged from 29 to 69 (mean=45.9, 
standard deviation=9.7). The pediatric visits averaged 15.2 minutes in length (standard deviation $=8.56$; range 1 to 45 minutes).

Caregiver ratings of providers using a participatory decision-making style ranged from 40 to 100 (mean=83.94, standard deviation=13.14). Fourteen percent of caregivers rated their providers as less than 70 on the participatory decision-making style scale. Child scores on the satisfaction scale ranged from 21 to 60 (mean=51.02, standard deviation=7.37). Caregiver scores on the satisfaction scale ranged from 102 to 182 (mean=166.2, standard deviation=17.2).

Table 2 presents the GEE results predicting child satisfaction. Caregiver rating of provider use of a participatory decision-making style was significant in the bivariate analysis (t-test= $-2.79, \mathrm{p}=0.006$ ), but it became non-significant in the multivariate analysis (beta $=3.77$ $\mathrm{p}=0.06$ ). Table 3 presents the GEE results predicting caregiver satisfaction. Visit length was not significantly related to child or caregiver satisfaction.

\section{Discussion and Conclusion}

\subsubsection{Discussion}

Caregivers were significantly more satisfied with providers who were rated as using more of a participatory style. This means that caregivers were more satisfied with providers who they perceived as involving them more in their child's treatment decisions. This is similar to the findings of a study that examined parent satisfaction with pediatric emergency room visits which found that if providers used a more patient-centered style they received higher ratings of providing good care [5]. The findings are also similar to a study conducted by Clark et al. (2008) which found that parents of asthmatic children had more positive perceptions of physicians if the providers listened carefully, inquired about home management, and had interactive conversation.

If providers want to improve caregiver satisfaction with pediatric asthma visits, they might attempt to involve caregivers more in treatment decisions. In fact, the 2007 National Heart Lung and Blood Institute expert panel report on the diagnosis and management of asthma emphasizes that providers should involve children and caregivers in treatment decisions [10].

Child satisfaction was significantly related to caregiver ratings of provider use of a participatory decision-making style in the bivariate analysis but it became insignificant in the GEE model. The study is limited in that we did not assess child ratings of provider use of a participatory decision-making style because we were concerned about respondent burden. Future work should assess child ratings of their provider's use of a participatory decisionmaking style. Providers may use more of a participatory style with caregivers than they do with children. The study is also limited in that we only examined caregiver perceptions of provider use of a participatory style. There is no way to know if a provider's use of a participatory decision-making style affects child or caregiver satisfaction or if caregivers who like their child's provider more have a more positive view of all of the provider's characteristics, including participatory decision-making style. Future work should examine actual provider use of a participatory decision-making style when asthma treatment decisions are made during visits.

Children were significantly more satisfied if they reported that their provider knew them better as a person. This finding illustrates the importance of providers taking the time to talk with children to get to know them better. The study is limited in generalizability in that it was conducted in five pediatric clinics in non-urban areas of North Carolina. Despite the 
limitations of the study, it provides new information on the relationship between caregiver perceptions of provider use of a participatory decision-making style and caregiver and child satisfaction with pediatric asthma visits.

\subsection{Conclusion}

Children were more satisfied with providers who they felt knew them better as a person. Children and caregivers were more satisfied with younger providers. Caregivers were significantly more satisfied with providers who they perceived as involving them more in their child's asthma treatment decisions.

\subsection{Practice implications}

Providers should attempt to use a more participatory decision-making style with families during pediatric asthma visits. Current national asthma guidelines in the United States state that providers should involve children and caregivers in treatment decisions [10].

\section{Acknowledgments}

This project was funded by the National Heart Lung and Blood Institute (Grant \# HL069837).

\section{References}

1. Childhood Asthma: The most common chronic disease among children. National Academy on an Aging Society website. 2000. http://www.agingsociety.org/agingsociety/pdf/asthma.pdf

2. Summary health statistics for US Children: National health interview survey. CDC website. 2008. http://www.cdc.gov/nchs/data/series/sr 10/sr10 244.pdf)

3. NHLBI. Guidelines for the Diagnosis and Management of Asthma. Expert panel report 2. NIH, National Heart Lung and Blood Institute Publication Number 97-4051; 1997 April.

4. NIH. NAEPP Expert Panel Report: Guidelines for the Diagnosis and Management of AsthmaUpdate on Specific Topics (02-5075). Washington, DC: 2002.

5. Wissow LS, Roter E, Bauman LJ, Crain E, Kercsmar C, Weiss K, Mitchell H, Mohr B. Patientprovider communication during the emergency department care of children with asthma. The National Institute of Allergy and Infectious Diseases, HIH, Bethesda, MD. Med Care. 1998; 36(10): 1439-1450. [PubMed: 9794338]

6. Clark NM, Cabana MD, Nan B, Gong, Slish KK, Birk NA, Kaciroti N. The clinical-patient partnership paradign: outcomes associated with physician communication behavior. Clinical Pediatrics. 2008; 47(1):49-57. [PubMed: 17901215]

7. Adams RJ, Smith BJ, Ruffin RE. Impact of the physician's participatory style in asthma outcomes and patient satisfaction. Ann Allergy Asthma Immunol. 2001; 86(3):263-271. [PubMed: 11289322]

8. Hart CN, Kelleher KJ, Drotar D, Schholle SH. Parent-provider communication and parental satisfaction with care of children with psychosocial problems. Patient Education and Counseling. 2007; 68:179-185. [PubMed: 17643912]

9. Freed LH, Ellen JM, Irwin CE, Millstein SG. Determinants of adolescents' satisfaction with health care providers and intentions to keep follow-up appointments. Journal of Adolescent Health. 1998; 22:475-479. [PubMed: 9627818]

10. Expert Panel Report 3 (EPR-3): Guidelines for the Diagnosis and Management of AsthmaSummary Report 2007. National Asthma Education and Prevention Program. J Allergy Clin Immunol. 2007 Nov; 120(5 Suppl):S94-S138. [PubMed: 17983880]

11. Cabana MD, Slish KK, Nan B, Clark NM. Limits of the HEDIS criteria in determining asthma severity for children. Pediatrics. 2004; 114:1049-1055. [PubMed: 15466104]

12. Lewis C, Scott D, Pantell R, et al. Parent satisfaction with children's medical care. Medical Care. 1986; 24:209-215. [PubMed: 3951263] 
13. Lewis C, Pantell R, Sharp L. Increasing patient knowledge, satisfaction, and involvement: randomized trial of a communication intervention. Pediatrics. 1991; 88:351-358. [PubMed: 1861939]

14. Bernzweig J, Takayama JI, Phibbs C, Lewis C, Pantell RH. Gender differences in physician-patient communication. Arch Pediatr Adolesc Med. 1997; 151:586-591. [PubMed: 9193244]

15. Kaplan SH, Gandek B, Greenfield S, Roger W, Ware JE. Patient and visit characteristics related to physicians' participatory decision-making style: Results from the Medical Outcomes Study. Medical Care. 1995; 33:1176-1187. [PubMed: 7500658]

16. Honeycutt C, Sleath B, Bush PJ, Campbell W, Tudor G. Physician use of a participatory decisionmaking style with children with ADHD and their parents. Patient Education and Counseling. 2005; 57:327-332. [PubMed: 15893216]

17. Rifkin L, Wolf MH, Lewis CC, Pantell RH. Children's perceptions of physicians and medical care: two measures. Journal of Pediatric Psychology. 1988; 13(2):247-254. [PubMed: 3171817]

18. Kroegel C, Wirtz H. History of guidelines for the diagnosis and management of asthma: from opinion to control. Drugs. 2009; 69(9):1189-1204. [PubMed: 19537836] 


\section{Table 1}

Child and caregiver demographic and child asthma-related characteristics $(\mathrm{N}=320)$

\begin{tabular}{|c|c|c|}
\hline & Mean (SD) or Percent (N) & Range \\
\hline Child age & $11.12(2.37)$ & $8-16$ years \\
\hline Child of female gender & $44.1(141)$ & \\
\hline \multicolumn{3}{|l|}{ Child race } \\
\hline White & $55.6(178)$ & \\
\hline African American & $29.7(95)$ & \\
\hline Native American/American Indian & $10.3(33)$ & \\
\hline Other & $4.1(13)$ & \\
\hline \multicolumn{3}{|c|}{ How well child thinks doctor knows them as a person } \\
\hline Hardly at all & $6.6(21)$ & \\
\hline Slightly & $13.8(44)$ & \\
\hline Moderately well & $24.1(77)$ & \\
\hline Very well & $55.3(177)$ & \\
\hline Caregiver age & $40.81(8.29)$ & $26-80$ years \\
\hline Caregiver education & $12.80(2.46)$ & $2-20$ years \\
\hline \multicolumn{3}{|l|}{ Caregiver race } \\
\hline White & $59.7(191)$ & \\
\hline African American & $28.1(90)$ & \\
\hline Native American & $7.8(25)$ & \\
\hline Other & $2.2(7)$ & \\
\hline Caregiver-female gender & $85.3(273)$ & \\
\hline \multicolumn{3}{|c|}{ How long has the family known the doctor } \\
\hline Less than one year & $12.2(39)$ & \\
\hline Between 1 and 2 years & $8.4(27)$ & \\
\hline Between 3 and 4 years & $14.4(46)$ & \\
\hline More than 4 years & $64.1(205)$ & \\
\hline \multicolumn{3}{|l|}{ Insurance type } \\
\hline None & $1.3(4)$ & \\
\hline Private insurance & $27.2(87)$ & \\
\hline Medicaid & $50.6(162)$ & \\
\hline NC Health Choice & $17.5(56)$ & \\
\hline Other & $2.5(8)$ & \\
\hline \multicolumn{3}{|c|}{ Child's Asthma-Related Characteristics } \\
\hline Years living with asthma & $6.04(3.85)$ & $0-16$ years \\
\hline \multicolumn{3}{|l|}{ Asthma severity } \\
\hline Mild persistent & $31.3(100)$ & \\
\hline Moderate/severe persistent & $68.1(218)$ & \\
\hline
\end{tabular}


Table 2

Generalized estimating equation results predicting child satisfaction with the medical visit $(\mathrm{N}=320)$

\begin{tabular}{lc}
\hline Independent Variables & Adjusted beta $(95 \%$ confidence interval $)$ \\
\hline Child gender-female & $-1.13(-2.91,0.65)$ \\
Child age in years & $0.80(0.52,1.09) * * *$ \\
Child race-White & $-0.60(-2.57,1.37)$ \\
Severity of asthma- moderate/severe & $0.35(-1.21,1.91)$ \\
Years living with asthma & $-0.24(-0.41,-0.07)$ \\
How well the provider knows you as a person & $2.87(2.09,3.65) * * *$ \\
Caregiver rating of provider use of a & \\
participatory decision-making style & $3.77(-0.17,7.71)$ \\
Provider gender-female & $-0.25(-1.96,1.46)$ \\
Provider race-White & $2.37(-1.32,6.05)$ \\
Provider age & $-0.10(-0.18,-0.01)^{*}$ \\
Length of visit & $0.01(-0.01,0.01)$ \\
\hline$*$ & \\
p $<0.05$, & \\
p $<0.001$ & \\
\end{tabular}


Table 3

Generalized estimating equation results predicting caregiver satisfaction with the medical visit $(\mathrm{N}=320)$

\begin{tabular}{lc}
\hline Independent Variables & Adjusted beta $(\mathbf{9 5 \%}$ confidence interval) \\
\hline Child's severity of asthma- moderate/severe & $0.22(-3.91,4.36)$ \\
Years living with asthma & $-0.58(-1.14,-0.02)^{*}$ \\
Caregiver age & $0.07(-0.16,0.29)$ \\
Caregiver gender & $-1.43(-5.93,3.07)$ \\
Caregiver race-White & $-0.11(-3.86,3.64)$ \\
Caregiver years of education & $0.65(0.20,1.10)^{*}$ \\
Provider gender-female & $-4.83(-7.83,-1.82)^{* *}$ \\
Provider race-White & $3.20(-3.13,9.54)$ \\
Provider age & $-0.21(-0.35,-0.06)^{* *}$ \\
How long have you and your family & \\
known the provider & $1.86(0.13,3.58)^{*}$ \\
Caregiver rating of provider use of a & \\
participatory decision-making style & \\
Length of visit & \\
\hline p $<0.05$, & \\
p $<0.001$ & \\
\hline
\end{tabular}

